\title{
Risk Factors of Premature Rupture of Membrane in A Tertiary Care Hospital, Bangladesh
}

\author{
Most. Sabina Yeasmin ${ }^{1 *}$ \\ M. Jalal Uddin ${ }^{2}$ \\ Rajat Sanker Roy Biswas ${ }^{3}$ \\ Azwad Azdar ${ }^{4}$ \\ Shahanara Chowdhury ${ }^{5}$ \\ Nishat Anjum Nourin ${ }^{6}$
}

'Department of Obstetrics \& Gynaecology Chattogram Maa-O-Shishu Hospital Medical College Chottogram, Bangladesh.

${ }^{2}$ Department of Community Medicine

Chattogram Maa-O-Shishu Hospital Medical College Chottogram, Bangladesh.

${ }^{3}$ Department of Medicine

Chattogram Maa-O-Shishu Hospital Medical College Chottogram, Bangladesh.

${ }^{4}$ Department of Surgery

Chattogram Maa-O-Shishu Hospital Medical College Chottogram, Bangladesh.

${ }^{5}$ Professor of Obstetrics \& Gynaecology

Chittagong Medical College

Chottogram, Bangladesh.

${ }^{6}$ Chittagong Medical College

Chottogram, Bangladesh.

*Correspondence to:
Dr. Most. Sabina Yeasmin
Associate Professor
Department of Obstetrics \& Gynaecology
Chattogram Maa-O-Shishu Hospital Medical College
Chottogram, Bangladesh.
Mobile : 8801914339095
Email : drsabinah@yahoo.com

Date of Submission : 28.04 .2020

Date of Acceptance : 29.07 .2020

www.banglajol.info/index.php/CMOSHMCJ

\begin{abstract}
Background : Premature Rupture of Membrane (PROM) is one of the most common complication of pregnancy. A woman with premature rupture of membrane is at risk of perinatal morbidity and mortality and also associated with maternal morbidity and psychological stress. Objective of this study was to determine incidence and risk factors of pregnant woman with PROM admitted in a tertiary hospital at Chattogram, Bangladesh.
\end{abstract}

Materials and methods : This prospective observational study conducted in the Department of Obstetrics and Gynaecology at Chattogram Maa-O-Shishu Hospital

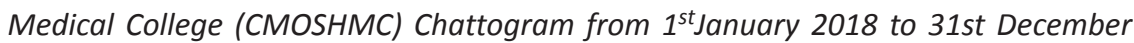
2018. In this period total admitted antenatal patients were 8117. Among the pregnant patients with PROM were 665 and their weeks of gestation were $>28$ weeks. Data was collected by interviewer with semi structured questionnaire \& check list.

Results : Incidence of PROM was $8.2 \%$. PROM was found to be frequent (53\%) in younger age group between 20-24 years. It was also commonly in primigravida (61.8\%). Term PROM was higher (69.2\%) than pre-term PROM (30.8\%). 93.3\% were singleton pregnancies, $6.4 \%$ were twins and $.3 \%$ were triplets. Analysis of risk factors revealed ectiology was unknown in 46 (6.8\%) low socioeconomic condition (60.6\%), anaemia (45\%), lower genital tract infection (35.6\%) UTI (31\%) previous history of PROM (27.9\%) malpresentation (15\%) multiple pregnancy (6.7\%) polyhydramnios (6\%) history of recent coitus (12\%) DM and GDM (10.5\%) were commonly associated with PROM.

Conclusions : Early identification of various risk factors causing PROM and their management can prevent premature deliveries and its complications to some extent as well as serious maternal complication like Chorioamnionitis.

Key words : Premature rupture of membrane; Risk factors; Pragnancy.

\section{INTRODUCTION}

Premature Rupture of the Membrane (PROM) is a common obstetrics problem and the assessment of women with possible membrane rupture is a management issue faced in every day practice ${ }^{1}$.

Worldwide, there is a slight difference in the prevalence of premature rupture of membranes and this could be due to the difference in the population studied. The incidence of PROM ranges from about $5 \%$ to $10 \%$ of all deliveries and PROM occurs in approximately $3 \%$ of all pregnancies. Approximately $70 \%$ of cases of PROM occur in pregnancies at term, but in referral centers, more than $50 \%$ of cases may occur in preterm pregnancies. PROM is the cause of about one third of all preterm birth ${ }^{2}$. PROM is a significant cause of perinatal morbidity \& mortality. The burden of PROM ranges from maternal and neonatal mortality and morbidity to national economic loss due to drug expense, hospitalization, absence from the workplace and expense to the health professionals ${ }^{3}$. 
Prediction and prevention of PROM would offer the best opportunity to prevent its complications. The risk factors of PROM include prior preterm birth, cigarette smoking, polyhydramnios, urinary and sexually transmitted infection, prior PROM, work during pregnancy, low body mass index, bleeding, low socioeconomic status ${ }^{3}$.

Previous studies to identify the risk factors of PROM were done at different countries. But the studies about identification of the risk factors of PROM in Bangladesh is very limited till now. Therefore we conducted the study to fill this gap by determining the risk factors of PROM.

\section{MATERIALS AND METHODS}

This prospective observational study was conducted at the Department of Obstetric and Gynaecology, CMOSHMC, Chattogram, Bangladesh, from 1st January 2018 to 31st December 2018. All the admitted pregnant patients with PROM were included in the study and all patient's weeks of gestations were $>$ 28 weeks. In the study period total number of admitted antenatal patients were 8117. Among them pregnant patients with PROM were 665 . Thorough history was taken followed by relevant clinical examination and some baseline investigations were done. All information were recorded in a structured questionnaire and check list.

\section{RESULTS}

During the 12 months of study, there were 8117 admitted pregnant patients, of which 665 cases of spontaneous PROM were seen, giving an incidence of $8.2 \%$ in our study.

Maximum cases belonged to age group 20-24 years (53\%) \& mean age of the patients were 24.8 years . Majority of the patients were housewife $(73.7 \%)$. Most of the cases came from urban area (66.4\%). Maximum (37.7\%) patient's education level were up to secondary. PROM is extremely influenced by low socioeconomic status which was $(60.6 \%)$ of cases in our study (Table I).

Table I : Demographic characteristics of the patients with PROM.

\begin{tabular}{|c|c|c|c|c|}
\hline SL. & Variables & Category & $\begin{array}{c}\text { No. of } \\
\text { patients }\end{array}$ & Percentage \\
\hline 1 & Age (Years) & $\begin{array}{l}15-19 \\
20-24 \\
25-29 \\
30-34 \\
>35\end{array}$ & $\begin{array}{r}23 \\
359 \\
195 \\
67 \\
21\end{array}$ & $\begin{array}{r}3.4 \% \\
54 \% \\
29.3 \% \\
10.08 \% \\
3.16 \%\end{array}$ \\
\hline 2 & Education level & $\begin{array}{l}\text { Illiterate } \\
\text { Primary } \\
\text { Secondary } \\
\text { Higher } \\
\text { secondary \& } \\
\text { above }\end{array}$ & $\begin{array}{l}108 \\
149 \\
251\end{array}$ & $\begin{array}{l}16.2 \% \\
22.4 \% \\
37.7 \%\end{array}$ \\
\hline
\end{tabular}

\begin{tabular}{|c|c|c|c|c|}
\hline \multirow[t]{3}{*}{3} & Occupation & Housewife & 490 & $73.7 \%$ \\
\hline & & Employee & 132 & $19.8 \%$ \\
\hline & & Others* & 43 & $6.5 \%$ \\
\hline \multirow[t]{3}{*}{4} & Residence & Urban & 442 & $66.4 \%$ \\
\hline & & Slum & 93 & $13.9 \%$ \\
\hline & & Rural & 130 & $19.7 \%$ \\
\hline \multirow[t]{4}{*}{5} & Socioeconomic & & & \\
\hline & status & Low & 403 & $60.6 \%$ \\
\hline & & Middle & 170 & $25.6 \%$ \\
\hline & & High & 92 & $13.8 \%$ \\
\hline
\end{tabular}

*Student, Maid servant, Daily labor.

Majority of the patients were primigravida (61.8\%) presented with term (>37 weeks) PROM (69.2\%) \& booked cases were $(70.5 \%)$. The mean gestational age at the onset of membrane rupture was 34.1 weeks. Multiple pregnancy was (6.7\%) among them twins \& triplets were $(6.4 \%) \&(0.3 \%)$ respectively. Highest number of patients had previous history of PROM (27.9\%). 15\% patients had history of spontaneous abortion \& $10 \%$ history of preterm delivery. Previous history of MR and $\mathrm{D} \& \mathrm{C}$ were $7.9 \%$ and $3.9 \%$ respectively (Table II).

Table II : Obstetric characteristics of the patients with PROM.

$\begin{array}{ll}\text { S.L No. Variables Category } & \begin{array}{l}\text { Number of Percentage } \\ \text { patients }\end{array}\end{array}$

$\begin{array}{cllll}1 & \text { Gravidity } & \text { Primigravida } & 411 & 61.8 \% \\ & & \text { Multigravida } & 254 & 38.2 \% \\ & & & \\ & & & \\ & \text { Gestational } & 28-36 \text { weeks + } 6 \text { days } & & \\ \text { age } & & 205 & 30.8 \% \\ & & & & \\ & & & \end{array}$

3 Antenatal Booked (at least 3

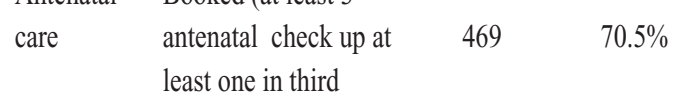

trimester)

Un booked $(<3$ antenatal

check up) $\quad 196 \quad 29.5 \%$

$4 \quad$ Number of $\quad$ Single $\quad 620 \quad 93.3 \%$

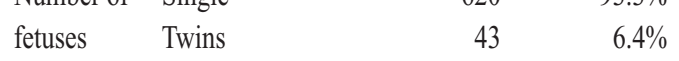

Triplets $\quad 2 \quad 0.3 \%$

$5 \quad$ Past obstetric History of

history spontaneous abortion $\quad 95 \quad 14 \%$

History of PROM $\quad 186 \quad 28 \%$

History of preterm delivery $66 \quad 10 \%$

History of M.R $\quad 53 \quad 08 \%$

History of D\&C $\quad 25 \quad 04 \%$

Nothing $\quad 240 \quad 36 \%$ 
Regarding various risk factors associated with PROM in our study, most of the cases (46.6\%) were unknown. Anaemia was the most $(45 \%)$ important and common risk factors there after lower genital tract and urinary tract infection were $35.6 \%$ \& $31 \%$ respectively. DM \& GDM were $10.5 \%$, increase frequency of coitus $12 \%$, Malpresentation $15 \%$, Multiple gestation $6.7 \%$, Polyhydramnios $6 \%$, pregnancy induced hypertension $13.5 \%$, only $1(0.15 \%)$ cases were cervical circlage in our study (Table III).

Table III : Risk factors of PROM.

$\begin{array}{llrr}\text { S.L No. } & \text { Variables } & \begin{array}{c}\text { Number of } \\ \text { patients }\end{array} & \text { Percentage } \\ & & 310 & 46.6 \% \\ 1 & \text { Idiopathic } & 299 & 45 \% \\ 2 & \text { Anaemia } & 208 & 31 \% \\ 3 & \text { Urinary tract infection } & 237 & 35.6 \% \\ 4 & \text { Lower genital tract infection } & 70 & 10.5 \% \\ 5 & \text { DM \& GDM } & & \\ 6 & \text { Increase frequency of coitus } & 83 & 12 \% \\ & \text { (Once / twice a week) } & 98 & 15 \% \\ 7 & \text { Malpresentation } & 45 & 6.7 \% \\ 8 & \text { Multiple gestation } & 38 & 6 \% \\ 9 & \text { Polyhydramnious } & 90 & 13.5 \% \\ 10 & \text { PIH } & 1 & 0.15 \% \\ 11 & \text { Cervical circlage } & & \end{array}$

\section{DISCUSSION}

The cause of PROM is multifactorial. In our country true incidence of PROM is very difficult to ascertain because more than $80 \%$ deliveries occur at home. Incidence among such a small number of patients does not reflect the total hospital incidence of the nation. In our study incidence of PROM was $8.2 \%$, of which term PROM 5.7\% and preterm PROM 2.5\%. Begum A et al, Choudhary $\mathrm{M}$ et al and Nazneen $\mathrm{S}$ et al in their study showed hospital incidence of PROM 9.05\%, 9.8\% and 6.3\% respectively which were close to our study ${ }^{4-6}$. Another study done by Begum $\mathrm{N}$ reported an incidence of $9.04 \%$. But almost similar rate $(8.12 \%)$ was reported in a study done by Tasnim $\mathrm{S}^{7,8}$.

Majority (53\%) of the patients belonged to the age group 20-24 years which is similar to the studies done by Begum A et al, Nazneen $\mathrm{S}$ et al and Tasnim $\mathrm{S}^{4,6,8}$.

Most of the patient's (73.7\%) were housewife which was higher than the study showed by Assefa $\mathrm{N}$ et al which was $58.8 \%{ }^{9}$. Most of the women in our country are housewife so the incidence is higher in comparison to their study.

Highest group of patient's (37.7\%) education level was secondary level which is close to the study by Mohan S et al which was $40.2 \%^{10}$. In our study $66.4 \%$ patients came from urban, as it is a tertiary care private hospital. Which was close $(65.4 \%)$ to the another study done by other private tertiary care hospital ${ }^{11}$. Low socio economic status is an important risk factor. In our study $60.6 \%$ patients came from low socio economic status which was higher than the study done by Mohan $\mathrm{S}$ et al where it was $55.2 \%{ }^{10}$. In the study done by Begum N, low socioeconomic status was $50 \%{ }^{7}$. In present study maximum $(61.8 \%)$ cases with PROM were primigravida which was almost similar $(62.7 \%)$ and $(53.33 \%)$ to the study done by lovereen $\mathrm{S}$ et al and Begum A et al respectively ${ }^{12,4}$. According to Akhter et al chance of increase sexual activity and increased genital infection are the most common among primigravida and in their study primigravida were $53 \%{ }^{13}$. Incidence of preterm PROM in our study was $30.8 \%$ which was almost similar $(29.09 \%)$ to the study by lovereen $\mathrm{S}$ et $\mathrm{al}^{12}$.

Although it is widely accepted that aetiology of PROM are multifactorial. Our study shows that most of the causes are idiopathic $(46.6 \%)$ which is similar to the study done by lovereenset al and in their study it was $47.3 \%{ }^{12}$. Anaemia is one of the most important risk factors of PROM which is $45 \%$ in our study and almost similar ( $44.5 \%$ ) to the study done by another private tertiary care Hospital but $26 \%$ and $16 \%$ was in the study done by Akhter $\mathrm{S}$ et al, Choudhary $\mathrm{M}$ et al respectively ${ }^{13,1,5}$. In our study lower genital tract infection was $35.6 \%$ which was almost near to the study done by another private tertiary care hospital where findings was $36.3 \%{ }^{11}$.

Another important risk factor of PROM is urinary tract infection which was $31 \%$ in our study and almost similar to the study done by another private tertiary care hospital and Begum A et al where prevalence were $31.8 \%$ and $33.33 \%$ respective$1 y^{11,4}$. Anaemia, hypertension and diabetes are associated risk factors of PPROM by affecting nutrition and immunity of the patient produce PROM ${ }^{14,15}$. In our study incidence of PIH, DM \& GDM are $13.5 \%$ and $10.5 \%$ respectively, which is higher than the study of Choudhary $\mathrm{M}$ et al, Mohan $\mathrm{S}$ et al and Akhter S et al where incidence was PIH (13\%) and DM (1.03\%) (4\%) respectively ${ }^{5,10,1}$.

Malpresentation is also one of the common risk factors for PROM. In our study malpresentation was $15 \%$ which was consistent with the study of Choudhary $\mathrm{M}$ et al and Miller et $\mathrm{al}^{5,16}$. They found malpresentation $14 \%$ and $13.9 \%$ of PROM cases respectively. Delayed or non-engagement of presenting part causes transfer of increased pressure to fore water. This resulted in weakening of dependent part of membranes followed by rupture. Over distention of the uterus by either multiple gestation and polyhydramnios also increase the risk of PROM by increasing the intrauterine tension and in this study these were $6.7 \%$ \& $6 \%$ respectively and which were consistent with the study of Choudhary $\mathrm{M}$ et $\mathrm{al}^{5}$. They showed that multiple gestation \& polyhydramnios $7.5 \%$ and $6 \%$ respectively. Increased frequency of coitus (Once / twice a week) in last trimester increases risk of PROM by causing ascending infection (Specially in predisposed cases like anaemia, GU infection, cervical circlage or damaged cervix) as well as increases uterine activity through prostaglandins present in semen ${ }^{5}$. Our study, showed PROM in $12 \%$ cases, when history of recent coitus was present, which was consistent with 
the study of Choudhary $M$ et al where they found $11 \%$ of PROM with history of increased frequency of recent coitus ${ }^{5}$. In our study, previous history of PROM was $27.9 \%$. Another important risk factors which was consistent with the study of Choudhary M et al, Mohan S et al, Lovereen S et al and Shehla $\mathrm{N}$, they showed that previous history of PROM $29 \%, 28.6 \%$, $16.3 \%$ \& $30.6 \%$ respectively $5,10,12,17$. History of spontaneous abortion $15 \%$ which was almost similar to the study by Mohan $\mathrm{S}$ et al where it was $17.7 \%{ }^{10}$. History of preterm delivery due to PROM is $10 \%$ which is similar to the study done by Akhter S et al and near to study done by Mohan $\mathrm{S}$ et al where it was $12.2 \%{ }^{1,10}$. History of MR \& D\&C in our study $7.9 \%$ and $3.9 \%$ respectively which were consistent with the study of Akhter S et al where incidence were $8 \%$ and $4 \%$ respectively ${ }^{1}$.

\section{CONCLUSION}

PROM is encountered to be one of the most common clinical events which turn a normal traditional pregnancy suddenly into a high-risk one for both the mother and the fetus. This study focused on risk factors in relation to PROM which can be preventable by proper health education, improved health hygiene, early diagnosis and treatment of genitourinary infections.

\section{ACKNOWLEDGEMENT}

The authors are thankful to all the faculty and staff members of the Department of Obstetrics and Gynaecology, Chattogram Maa-O-shishu Hospital Medical College and the patients for their immense cooperation and support during the period.

\section{DISCLOSURE}

All the authors declared no competing interest.

\section{REFERENCES}

1. Akter S. Akther R. Rashid Z. Pretermpre labour rupture of the membrane and feto-maternal outcome: An observational study, J Bangladesh Coll Phys Surg. 2010;28:1:17-23.

2. Gibbs R, Karlan B , Haney A, Nygaard I Danforth's obstetrics and gynaecology. $10^{\text {th }}$ ed Philadelphia: Lipincort Wlliams \& wilkins. 2008.

3. Gabbe SG, Niebyl JR, Simpson JL obstetrics Normal and problem pregnancies. $5^{\text {th }}$ ed: Ed: Churchil Livingstone. 2007.

4. Begum A, Ghani T, Paul SK,. Hussain T, Noor Jahan, Begum N. Outcome of premature rupture of membranes -A study of 120 scases in Dhaka Medical College Hospital. J Dhaka Med Coll. 2016;25(2):82-86.s

5. Choudhary M, Rathore S, Chowdhary J, Garg S. Pre and post conception risk factors in PROM.Int J Res Med Sci. 2015;3(10):2594-2598

6. Nazneen S, Begum F, Nargis S.Prematue Rupture of Membrane- A clinical study in Comilla Medical College Hospital. Bangladesh J Obstet Gynaecol. 2013;28(2): 82-87.

7. Begum N. Epidemiology of premature Rupture of Membrane and Management in Rangpur Medical College Hospital. Dissertation, Bangladesh College of Physicians and Surgeons. 2004.

8. Tasnim S. Clinical profile and outcome of pregnancy in premature rupture of memebrane in Dhaka Medical College Hospital.as study of fifty-five cases (Dissertation) Dhaka. Bangladesh College of Physicians and Surgeons. 1995.

9. Assefa N, Berhe H, Girma F,Berhe K, Berhe Y, Gebreheat G, Werid W, Berhe A, Rufae H, WeluG.Risk factors of premature rupture of membranes in public hospitals at Mekele city, Tigray, a case control study. BMC pregnancy and child birth. 2018;18:386.

10. Mohan S, Thippeveeranna C. Singh N, Singh L: Analysis of risk factors, maternal and fetal outcome of spontaneous preterm premature rupture of membranes: A cross sectional study.Int J Reprodcontraceptobstet Gynecol. 2017;6(9):3781-3787.

11. Afza N, Nargis W, Ahmaed B, Sikder N:The incidence, Risk Factors and Common foetal outcome of chorioamnionitis in Women with preterm premature Rupture of Membrane (PPROM): A single Centre Study.Bangladesh, J obstetgynaecol. 2011;26(1):10-19.

12. Lovereen S, Khanum A, Nargis N, Begum S, Afroze R Maternal and neonatal outcome in premature rupture of membranes.Bangladesh journal of medical Science. 2018;17(3):479-483

13. Akhter Ms, Degan JS, Akter UA, D Sharman PROM study of 300 cases and review of literature. J Obstet \& Gynecol of India. 1980;30:81.

14. Griff Jones :Pre labour rupture of the membrane, Obstetrics and Gynaecology -An evidenced based text for MRCOG, Arnold, Member of the hodder headline group.W W W. Arnold publishers .com; $1^{\text {st }}$ edition; Oxford University press. 2004;297.

15. AshleyS.Roman, MD, MPH \& Martin L. Pernoll. MD. Late pregnancy complication, Current obstetric \& Gynaecologic Diagnosis and treatment. $8^{\text {th }}$ edition. Appleton \& Lange. 1994;286-287.

16. Miller JM, Pupkin MJ. Premature labour and premature rupture of membranes.Amer J Obstet\& Gynae.1978;132:1-4

17. Shehla N, Prevalence of PPROM and its outcome. J Ayub Med. College abbottabad J of obstet Gynecol. 1899;29(4):223-228. 